\title{
KEYWORD INDEX TO VOLUME 1
}

Anarchy 21

Belief 149

Biology 42

Callon 72

Critical realism 42

Doctor 72

Durkheim 4

Economy 91

Explanatory models 149

Gender 108

Global health 21

Globalization 21, 91

Governance 21

Health 42, 72

Health and illness 130

Health behaviour 149

Health inequality 108

Historical sociology 130
Individualism 4

Industrialization 91

Inequalities 42

Inequality 4

International relations theory 21

Interpretivism 42

Military power 91

Modernity 91

Neo-liberalism 4

Positivism 42

Power 130

Practice 42

Public health 21

School 72

Social capital 4

Social policy 108

Structure-agency 42

Trust 72 